\title{
Restraint of Acetaminophen - Induced Liver Injury with Butylated Hydroxyanisole and Butylated Hydroxytoluene, and Its Effects on Hepatic Heat Shock Protein 25 and 70i
}

\author{
Jinhua Boindogurong*, Yukari Egashira and Hiroo Sanada \\ Laboratory of Food and Nutrition, Graduate School of Science and Technology, Chiba University \\ (648 Matsudo, Matsudo-shi, Chiba, 271-8510, JAPAN)
}

Edited by T. Itoh, Kitasato Univ., and accepted January 11, 2005 (received for review August 30, 2004)

\begin{abstract}
We examined the effects of butylated hydroxyanisole (BHA) and butylated hydroxytoluene (BHT) on acetaminophen - induced hepatotoxicity using two different administration methods; i.e, feeding rats with BAH- and BHT- added diets, and by direct oral administration. In the former case, BHA and BHT $(0.5 \%$ each $)$ were separately added to experimental diets which were given to rats for 7 days, and then after a $16 \mathrm{~h}$ - fast, APAP $(500 \mathrm{mg} /$ $\mathrm{kg}$ ) was intraperitneally given. The oral administration of BHA or BHT $(125 \mathrm{mg} / \mathrm{kg}$ body weight) was carried out $2 \mathrm{~h}$ before the APAP treatment. The elevation of the plasma AST and ALT activities as an index of liver injury was significantly suppressed in the BHA- and BHT- fed groups at $24 \mathrm{~h}$ after the APAP treatment and significantly lower levels in the BHA oral pretreatment group were seen when compared with those in the APAP group. On the other hand, the BHT oral pretreatment group showed rather high AST and ALT activities. The restraint function was clarified when BHA and BHT were fed, and also when BHA was orally administered, although a similar function was not observed in case of the oral administration of BHT. The inductions of Hsp25 and Hsp70i by APAP were not depressed by the BHA administration, but were suppressed by the BHT except in the case of Hsp70i in the group orally given BHT. These results suggest that BHT blocks NAPQI to covalently bind to the cellular macromolecules, although BHA does not.
\end{abstract}

Key words: butylated hydroxyanisole (BHA), butylated hydroxytoluene (BHT), acetaminophen, hepatotoxicity, heat shock protein 25 , heat shock protein $70 \mathrm{i}$, rat

\section{Introduction}

The heat shock proteins (Hsps) are ubiquitous in nature and can be grouped into a number of distinct families based on their molecular size and amino acid sequence relationships. Among such proteins, Hsp90, Hsp70, Hsp60, Hsp40 and Hsp25 (Hsp27 for humans) are widely known. The Hsp synthesis is induced by heat stress, as well as other various adverse stimuli; for example, several hepatotoxicants, including acetaminophen, carbon tetrachloride, bromobenzene and cocaine (1-3). When treated with hepatotoxic doses of cocaine (2) and acetaminophen $(1,3)$, mice had elevated hepatic levels of Hsp25 and Hsp70i. The transcriptional induction of the Hsp genes induced by stress is mediated by the heat shock transcription factor 1 (HSF1) $(4,5)$. This seems to result from non-native proteins which exist in the cells (6-8). Proteins, when adducted by reactive hepatotoxicant metabolites, could possibly make themselves have a non-native nature. This enables them to set off

\footnotetext{
* Correspondence to: Jinhua Boindogurong, Laboratory of Food and Nutrition, Graduate School of Science and Technology, Chiba University, 648 Matsudo, Matsudo-shi, Chiba, 271-8510, JAPAN

E-mail: huajin25@hotmail.com
} 
the activation of HSF1, thereby expanding the Hsp synthesis.

An overdose of acetaminophen (APAP) causes acute liver necrosis. Due to the action of cytochrome P450, APAP is metabolized to $N$-acetyl-benzoquinone-imine (NAPQI) which can conjugate with a detoxifier glutathione (GSH). NAPQI acts as a hepatotoxin when $\mathrm{GSH}$ is depleted. While there are still many possible nucleophilic targets in the cell, certain proteins are preferentially bound by NAPQI, and their adduction has been proposed to play a role in causing cell death $(9$, $10)$.

It was shown in our previous study (11) that butylated hydroxyanisole (BHA) and butylated hydroxytoluene (BHT) had no effect on CYP2E1 and both of them contributed to the earlier recovery of the GSH concentration level in the liver. In this study, the experiments were conducted to compare the different effects of BHA and BHT given in the 2 different ways; the first one was feeding rats with BHA- or BHT- added diets for 7 days and the second one was providing them with an oral administration. We examined the effect of BHA and BHT on Hsp25 and 70i in order to clarify the mechanism of their protective action against the APAP liver injury.

\section{Materials and Methods}

\section{$2 \cdot 1$ Chemicals}

APAP was purchased from the Sigma Chemical Co. (St. Louis, MO, U.S.A.) and IATROZYME TA-L diagnostic kit for plasma alanine aminotransferase (ALT) and aspartate aminotransferase (AST) measurements were obtained from the Iatron Co. (Iatron Laboratories, Inco, Tokyo, Japan). The rabbit anti - Hsp70i polyclnal antibody, rabbit anti - Hsp25 polyclonal antibody and goat anti - rabbit IgG: HRP horseradish peroxidase conjugated antibody were purchased from Stressgen Biotechnologies Corp. (Victoria, BC, Canada). BHA, BHT, phenylmethylsulfonyl fluoride (PMSF) and all other chemicals were purchased from Wako Pure Chemical Industries, Ltd. (Osaka).

\section{$2 \cdot 2$ Animals and Experimental Design}

Five - week - old male Wistar - SPF rats (SLC Co., Japan) were individually kept under a $12 \mathrm{~h}$ light/dark cycle. The rats were treated in accordance with the National Institutes of Health Guide for Care and Use of
Laboratory Animals. They were given the same treatment as described in the previous paper for experiment 1. After the four - day standard diet, one each in the two groups was given an experimental diet containing BHA $(0.5 \%)$ or BHT $(0.5 \%)$ and the other two groups received the standard diet only for 7 days. Three of these four groups (except one standard diet group) were then intraperitoneally treated with APAP at a dose of $0.5 \mathrm{~g}$ per $\mathrm{kg}$ body weight after fasting for $16 \mathrm{~h}$. The normal control group received the same volume of saline instead of APAP.

For experiment 2, following the 4 - day standard diet and $16 \mathrm{~h}$ - fast as described above, BHA or BHT was orally administered in the amount of $125 \mathrm{mg} / \mathrm{kg}$ body weight. This amount corresponds to those of BHA and BHT taken by a rat per day during their feeding with the diet added $0.5 \%$ BHA and $0.5 \%$ BHT, respectively, APAP was then intraperitoneally injected after two hours. Six hours following the APAP dosing, the rats were refed their respective diets they had previously received, and at $24 \mathrm{~h}$, they were killed by decapitation. Blood and liver samples were collected and analyzed as follows.

\subsection{ALT and AST Activities of Plasma}

The ALT and AST levels in the plasma were determined using a commercial assay kit according to the manufacturer's instructions.

\subsection{Preparation of Rat Liver Microsome and Cytosol and Western Immunoblots of Hsps}

The liver samples were homogenized in 4 vol. of ice cold $100 \mathrm{mM}$ tris (hydroxymethyl) aminomethane (Tris) - acetate buffer $\mathrm{pH} 7.5$ containing $250 \mathrm{mM}$ sucrose, $1 \mathrm{mM}$ EDTA, and $1 \mathrm{mM}$ PMSF. The homogenates were centrifuged at $10,000 \times g$ and $4{ }^{\circ} \mathrm{C}$ for $10 \mathrm{~min}$ in order to remove the mitochondria. After centrifugation at $105,000 \times g$ and $4^{\circ} \mathrm{C}$ for $60 \mathrm{~min}$, the supernatants was used for the analysis of cytosol and the pellet for the microsome.

The protein content of the samples was measured according to the method of Lowry (12). For the immunoblotting, a sample buffer [0.05 M Tris - $\mathrm{HCl}$ (pH 6.8) containing 2\% SDS, $10 \mathrm{mM}$ DTT, $250 \mathrm{mM}$ sucrose, and $1 \mathrm{mM}$ PMSF] for eletrophoresis was added to the supernatant of each sample and them an aliquot of each sample containing $50 \mu \mathrm{g}$ of proteins. The 
cytosol proteins were electrophoretically separated on a $10 \%$ SDS polyacylamide gel and these proteins were transferred to a nitrocellulose membrane by the method of Towbin (13). The membrane blocking was completed by overnight incubation in 5\% skim milk/TTBS [0.05\% Tween 20, $50 \mathrm{mM}$ Tris - $\mathrm{HCl}$ (pH 6.8), 200 $\mathrm{mM} \mathrm{NaCl}$ ]. The membrane was then exposed to a polyclonal antibody (Rabbit anti - Hsp25 serum and Rabbit anti - Hsp70i serum) solution, at a 1:5000 (Hsp25) and 1:10000 (Hsp70i) dilution in TTBS containing $1 \%$ skim milk, and incubated at $37^{\circ} \mathrm{C}$ for $2 \mathrm{~h}$ with continuous shaking. After washing, the membrane was incubated with a solution of goat anti - rabbit IgG: HRP horseradish peroxidase conjugated antibody at a 1:10000 dilution in TTBS containing 1\% skim milk at $37^{\circ} \mathrm{C}$ for $1 \mathrm{~h}$ with continuous shaking. The immunoreactivity was visualized using the Western Lightning ${ }^{\mathrm{TM}}$ Chemiluminescence Reagent Plus (Perkin - Elmer Life Sciences, Inc.) and the membrane scanned with a Personal Laser Densitometer. The data were quantified using an Image Gauge.

\subsection{Statistical Analysis}

Data are shown as means $\pm \mathrm{SE}(\mathrm{N}=5)$. Data were analyzed by one - way ANOVA followed by Scheffe's multiple comparison tests to determine the significant differences between group means. The level of significance was taken as $\mathrm{P}<0.05$.

\section{Results and Discussion}

\section{3-1 APAP - Induced Liver Injury in Rats}

In experiment $1, \mathrm{BHA}$ and $\mathrm{BHT}$ were added to the diet at the rate of $0.5 \%$ each. Such diets were given to rats for 7 consecutive days. The AST and ALT activities for normal rats were 105.7 and 55.5 (IU/L). In experiment 2, BHA or BHT was orally given to rats $2 \mathrm{~h}$ before the APAP administration to examine the effects of BHA and BHT on the elevation of the plasma transaminase activities induced by APAP.

Figure 1 shows the effects of the BHA or BHT pretreatment on the plasma AST and ALT activities after the APAP administration. The activities of both enzymes in the APAP - treated rats with the BHA or BHT containing diet pretreatment were lower than those in the APAP treated with no pretreatment rats. In the BHA pretreatment rats, the AST activities were $1 / 11$ and the ALT activities were $1 / 14$, and in the BHT - pretreatment rats, the AST activities were $1 / 8$ and the ALT activities were $1 / 6$ of those of the no pretreatment rats, respectively. These results indicate that liver injury was prevented by this dose of BHA and BHT in agreement

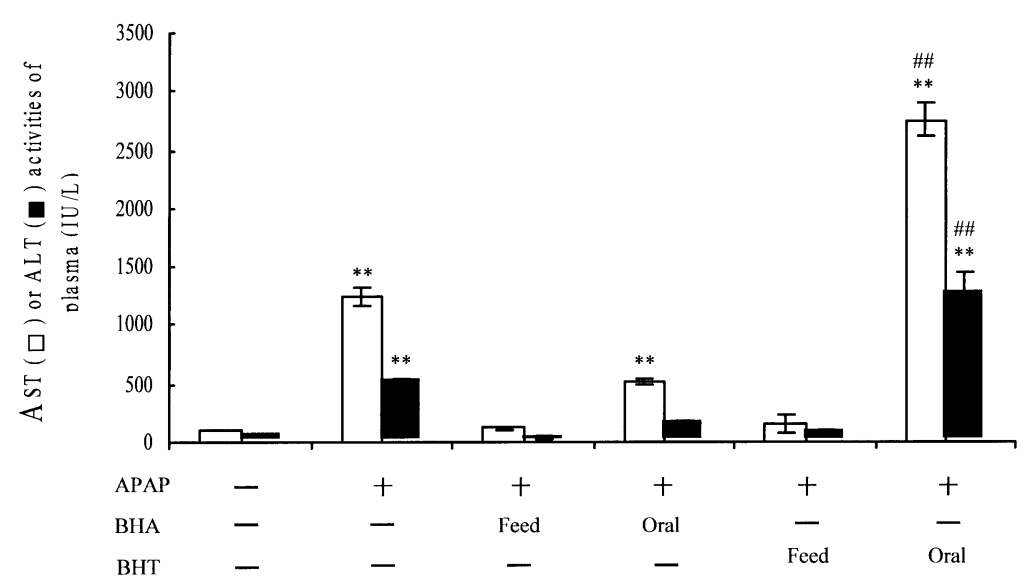

Fig. 1 Effect of APAP Administration (500mg/kg I.P.) on Plasma AST $(\square)$ or ALT ( $\square$ ) Activities in the Rats. Each point represents the means \pm SE of 5 rats. (a), Rats were given a one - week experimental diet containing BHA and BHT (0.5\% each). (b) BHA and BHT ( $125 \mathrm{mg} / \mathrm{kg}$ bw, each; P.O.) were administered at $2 \mathrm{hr}$ prior to the APAP treatment. $* * \mathrm{P}<0.01$ compared to the control levels. \#\# $\mathrm{P}<0.01$ compared to the APAP levels. 
with findings from a previous study (11).

The AST and ALT activities in the orally administered BHA - pretreatment rats were $2 / 5$ and $5 / 18$ of those of the no pretreatment rats, respectively, however, both activities in the orally administered BHT - pretreatment rats were 2 fold and 2.4 fold higher than the no pretreatment rats. Those values were 5.3 fold and 8.5 fold higher than the BHA pretreatment rats, respective1y. As a result, the BHA orally administered at $125 \mathrm{mg} / \mathrm{kg}$ body weight was suggested to suppress the APAP - induced hepatotoxicity, while the same amount of BHT was considered to have a negative effect on the development of liver injury by APAP.

These results suggested that BHA restrained APAP liver injury whenever it was orally administered or added to the diet. The same amounts of BHT added to the diet also had a strong suppressive effect on the APAP liver injury, however, deteriorate liver injury was observed when orally administered.

\section{$3 \cdot 2$ Effect of BHA and BHT on the Induc- tion of Hsp25 and Hsp70i in the Rat Liver after APAP Administration}

In this study, BHA and BHT ( $0.5 \%$ each) were separately added to the diet, and also, equivalent of one day's doses of BHA and BHT were orally administered. Consequently, no difference was observed in the hepatic microsomal and cytosolic proteins in all groups. The protein concentrations of the hepatic microsome and cytosol in the control rats were $24.0 \pm 0.9$ and $17.8 \pm$ $0.9 \mathrm{mg} / \mathrm{g}$, respectively. A previous paper described the increases in the hepatic microsomal and cytosolic protein contents in the female, but not male mice, following BHA treatment (14). According to the reports, BHA treatment did not affect the activities of the hepatic microsomal mixed - function oxidases in the rat, however, moderate changes have been observed with BHT. It was also reported that a number of hepatic enzymes were induced when BHA was added at $0.75 \%(\mathrm{w} / \mathrm{w})$ to the diet given for 10 days to mice (15).

Figure 2 shows representative Western blots of Hsp25 and Hsp70i in the liver of each group in experiments 1 and 2. For the 7 - day feeding of BHT, Hsp25 and Hsp70i were induced only $2 \%(\mathrm{P}<0.01)$ as compared to those from the no pretreatment rats. However, when BHT was orally administered, Hsp25 and Hsp70i were induced more than $16 \%(\mathrm{P}<0.01)$ and $91 \%$, respectively, compared to those without the BHT - pre-
(A)

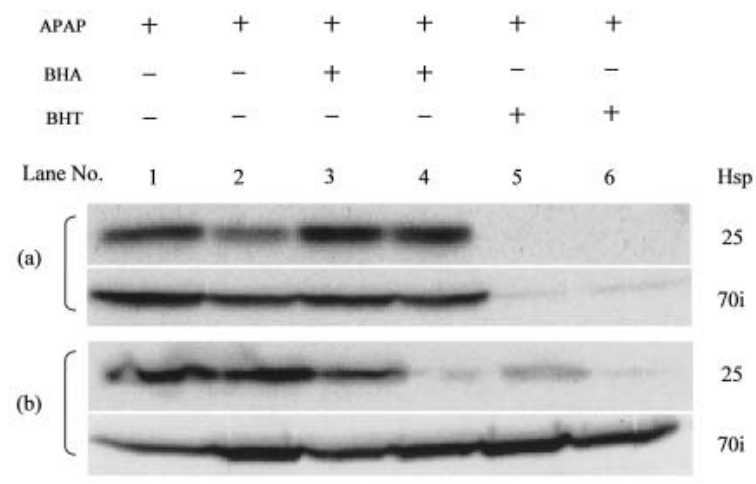

(B)

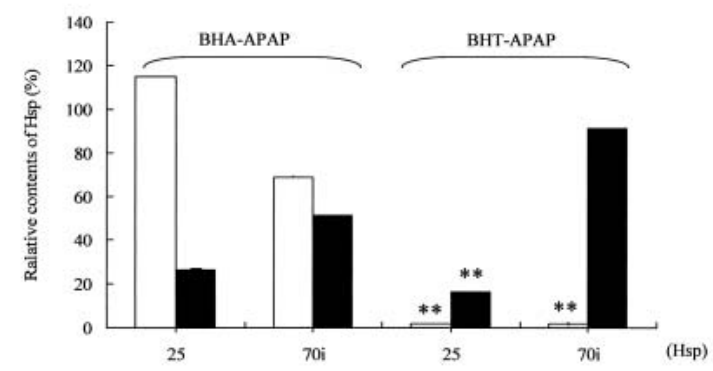

Fig. 2 The Western Blotting Hepatic Hsp25 and 70i Levels Following APAP Treatment. (A), The Western immunoblotting patterns of Hsps 24 $\mathrm{h}$ after APAP administration. Lane 1and 2, APAP; Lane 3 and 4, BHA + APAP; Lane 5 and 6 , BHT + APAP. (a), experimental diet containing BHA and BHT (0.5\% each) for 7 days. (b), BHA and BHT $(125 \mathrm{mg} / \mathrm{kg}$ bw, each, P.O.) were administered at $2 \mathrm{hr}$ prior to the APAP treatment. (B), Relative contents (\%) of Hsps at $100 \%$ of APAP group from BHA or BHT added diet ( $\square$ ), and oral administered (ם) groups. Result from scanning densitometry of Western immunoblots. The bars represent the means \pm SE of 4 individual rat liver homogenates within each group. ${ }^{* *}$ Values are significantly different from respective values of APAP group $(\mathrm{P}<0.01)$.

treatment rats. On the other hand, the BHA - pretreatment rats showed 70 to $115 \%$ of the no pretreatment rats irrespective of the administration methods. The Hsp25 and Hsp70i of the normal rats were not detected (Data not shown).

We presumed that BHA and BHT have protective effects against APAP - induced liver injury depending on the Hsp responsiveness by the following steps; the first, Hsps expression can be induced by acetaminophen 
including Hsp25 and Hsp70i $(1,3)$ and, second, Hsps protects against necrosis $(16,17)$. Some researchers have proved the function of Hsps to protect the liver against APAP - induced injury $(18,19)$. Hsp70i together with Hsp25 may function as a cytoprotective Hsp to "repair" the damaged protein in the necrotic lesion, and additionally, Hsp25 may act as a safeguard to block the inflammation spreading to the surrounding area (3). Based on these findings, we thought the more these proteins, the less the liver injury.

To estimate the amounts of Hsp25 and Hsp70i, we used western blot and densitometric analyses. The amounts of Hsp25 and Hsp70i with the pretreatment of BHA or BHT are not higher than those without the pretreatment, although the liver injury is restrained by the functions of BHA and BHT.

At normal dosage levels, $4 \%$ of APAP was oxidized to the highly reactive and toxic intermediate, $\mathrm{N}$-acetylbenzoquinone-imine (NAPQI), by the cytochrome P450 (CYP) (20-22) through the major metabolic pathways that include glucuronidation (52\%) and sulfation (42\%) (23). NAPQI has been detoxified by conjugation with glutathione (GSH). Although NAPQI fails to be completely detoxified by conjugation, some of the unconjugated NAPQI covalently binds to critical cellular macromolecules $(24,25)$ and the protein adduction that arises from this is thought to lead to liver injury, and ultimately to death in severe cases. BHA is considered to restrain APAP - induced liver injury by increasing the liver GSH content $(26,27)$. We have reported that the APAP - induced hepatotoxicity had been suppressed by not only BHA but also by BHT pretreatment. In case of BHA, the suppression occurred with an increase in the GSH content but the detoxification of APAP by BHT must have been performed through a different route than BHA (11). We supposed that BHT might induce an unknown compound $\mathrm{X}$ (such as certain kinds of proteins) that would conjugate with NAPQI, and the conjugates then protect from liver injury. As shown in Fig. 1, orally administered BHT could not protect from liver injury. Fig. 2A shows that small amounts of Hsp70i and Hsp25 in the BHT fed rats in their NAPQI are detoxified by compound X. Hsp25 was also suppressed but Hsp70i was induced in the BHT orally administered rats. It could be suggested that compound $\mathrm{X}$ might be induced and accumulated by the continuous administration of BHT for a while instead of only one administration. When compound $\mathrm{X}$ is not present,
Hsp70i might be induced by the APAP administration wherever BHT is present. The hepatic Hsp70i increased during the early stage of the APAP treatment. This may serve as an alternative protein target for NAPQI. In this case, Hsp25 may later work as an anti - inflammatory protein (3).

On the other hand, such a restraint of the induction of Hsp70i and Hsp25 was not observed in the BHA - pretreated rats. The increase in the intralobular reactive metabolite of APAP, NAPQI, bound with GSH and the increased concentrations of Hsp25 and Hsp70i might be in firm correlation. This is consistent with the report describing that protein adduction is a stimulus for Hsp synthesis (1). The increased amount or concentration of the adducted protein is expected to help the promotion of the Hsp synthesis. The Hsp25 anti - apoptotic activity may be explained by several mechanisms. The protein could expand the antioxidant defense of cells by increasing the cell content of glutathione (28), these by neutralizing the toxic effects of the oxidized protein by its chaperon activity (29). Based on the results of our previous study (11) and the present result, we came to assume that the increase in the liver GSH was related to the change in the Hsp25 amount, but not to the CYP2E1 amount.

\section{Conclusion}

Both BHA and BHT are chemically synthesized antioxidants. As xenobiotics, they are metabolized in a living body via the biotransformation pathway. In the liver, APAP is metabolized into NAPQI having a strong toxicity which might cause the Hsp25 and Hsp70i levels to elevate. It is our opinion that BHA and BHT affect the APAP - induced hepatotoxicity differently, through different "routes". In our previous paper, the increases in the GSH concentration of APAP administered rat livers showed a similar tendency whichever pretreatments were done with BHA or BHT. The GSH concentration in the BHA - pretreatment rats increased twice over that of the BHT - pretreatment rats. In this study, Hsp25 and Hsp70i are induced far less than our assumption due to addition of BHT. We think that BHT blocks covalent NAPQI binding to cellular macromolecules, although BHA does not. This is the first study concerning the heat shock protein in relation to the action of BHA and BHT against APAP - induced hepatotoxicity in rats. Since the molecular mechanism 


\section{J. Boindogurong, Y. Egashira and H. Sanada}

of the action of BHA and BHT is still unclear for the most part, further studies are necessary for its complete elucidation.

\section{References}

1. W.F. SALMINEN, R. VOELLMY and S.M. ROBERTS, Differential Heat Shock Protein Induction by Acetaminophen and a Non-Hepatotoxic Regioisomer, 3'-hydroxyacetanilide, in Mouse Liver, The Journal of Pharmacology and Experimental Therapeutics, Vol. 282, 1533-1540 (1997a).

2. W.F. SALMINEN, S.M. ROBERTS, M. FENNA and R. VOELLMY, Heat Shock Protein Induction in Murine Liver after Acute Treatment with Cocaine, Hepatology, Vol. 25, 1147-1153 (1997b)

3. I. SUMIOKA, T. MATSURA, M. KAI and K. YAMADA, Potentail Roles of Hepatic Heat Shock Protein 25 and 70i in Protection of Mice against Acetaminophen-Induced Liver Injury, Life Sci., Vol. 74, 2551-2561 (2004).

4. J.J. COTTO, M. KLINE and R.I. MORIMOTO, Activation of Heat Shock Factor 1 DNA Binding Precedes Stress-induced Serine Phosphorylation, J. Biol. Chem., Vol. 271, 3355-3358 (1996).

5. W. XIA and R. VOELLMY, Hyperphosphorylation of Heat Shock Transcription Factor 1 Is Correlated with Transcriptional Competence and Slow Dissociation of Active Factor Trimers, $J$. Biol. Chem., Vol. 272, 4094-4102 (1997).

6. J. ANANTHAN, A.L. GOLDBERG and R. VOELLMY, Abnormal Protein Serve as Eukaryotic Stress Signals and Trigger the Activation of Heat Shock Genes, Science, Vol. 232, 522-524 (1986).

7. S.A. GOFF and A.L. GOLDBERG, Production of Abnormal Proteins in E. coli Stimulates Transcription of Lon and Other Heat Shock Genes, Cell, Vol. 41, 587-595 (1985).

8. J. ZUO, D. RUNGGER and R. VOELLMY, Multiple Layers of Regulation of Human Heat Shock Transcription Factor 1, Mol. Cell. Biol., Vol. 15, 4319-4330 (1995).

9. J.B. BARTOLONE, R.B. BIRGE, S.J. BULERA, M.K. BRUNO, E.V. NISHANIAN, S.D. COHEN and E.A. KHAIRALLAH, Purification, Antibody Production, and Partial Amino Acid Sequence of the 58-kDa Acetaminophen-Binding Liver Proteins, Toxicol. Appl. Pharmacol., Vol. 113, 19-29 (1992).

10. R. BALER, G. DAHL and R. VOELLMY, Activation of Human Heat Shock Genes is Accompanied by Oligomerization, and Rapid Translocation of Heat Shock Transcription Factor HSF1, Mol. Cell. Biol., Vol. 13, 2486-2496 (1993).

11. J.H. BOINDOGURONG, T. HIGAKI, Y. EGASHIRA and H. SANADA, Protective Effect of Butylated Hydroxyanisole and Butylated Hydroxytoluene against Acetaminophen-Induced Hepatotoxicity in Rats, J. Oleo Sci., Vol. 54, 153-159 (2005).

12. O.H. LOWRY, N.J. ROSEBROUGH, A.L. FARR and R.J. RANDALL, Protein Measurement with the Folin Phenol Reagent, $J$.
Bio. Chem., Vol. 193, 265-275 (1951).

13. H. TOWBIN, T. STAEHELIN and J. GORDON, Electrophoretic Transfer of Proteins from Polyacrylamide Gels to Nitrocellulose Sheets: Procedure and Some Applications, Proc. Natl. Acad Sci. USA, Vol. 76, 4350-4354 (1979).

14. A.G. HAZELTON, J.J. HJELLE and C.D. KLAASEN, Effects of Butylated Hydroxyanisole on Hepatic Glucuronidation Capacity in Mice, Toxicol. Appl. Pharmacol., Vol. 78, 280-290 (1985).

15. Y.N. CHA and E. BUEDING, Effect of 2(3)-tert-butyl-4-hydroxyanisole Administration on the Activities of Several Hepatic Microsomal and Cytoplasmic Enzymes in Mice, Biochem. Pharmacol., Vol. 28, 1917-1921 (1978).

16. M. JAATTELA, Heat Shock Proteins as Cellular Lifeguards, Ann. Med., Vol. 31, 261-271 (1999).

17. C. GARRIDO, S. GURBUXANI, L. RAVAGNAN and G. KROEMER, Heat Shock Proteins: Endogenous Modulators of Apoptotic Cell Death, Biochem. Biophys. Res. Commun., Vol. 286, 433-442 (2001).

18. W.F. SALMINEN, R. VOELLMY and S.M. ROBERTS, Protection against Hepatotoxicity by a Single Dose of Amphetamine: The Potential Role of Heat Shock Protein Induction, Toxicol. Appl. Pharmacol., Vol. 147, 247-258 (1997).

19. H. CHIU, J.A. BRITTINGGHAM and D.L. LASKIN, Differential Induction of Heme Oxygenase-1 in Macrophages and Hepatocytes during Acetaminophen-Induced Hepatotoxicity in the Rat: Effects of Hemin and Biliverdin, Toxicol. Appl. Pharmacol., Vol. 181, 106-115 (2002).

20. J.R. MITCHELL, D.J. JOLLOW, W.Z. POTTER, D.C. DAVIS, J.R. GILLETTE and B.B. BRODIE, Acetaminophen-Induced Hepatic Necrosis. I. Role of Drug Metabolism, J Pharmacol Exp. Ther., Vol. 187, 185-194 (1973).

21. D.J. JOLLOW, J.R. MITCHELL, W.Z. POTTER, D.C. DAVIS, J.R. GILLETTE and B.B. BRODIE, Acetaminophen-Induced Hepatic Necrosis. Role of Covalent Binding in vivo, J Pharmacol Exp. Ther., Vol. 187, 195-202 (1973).

22. J.A. HINSON, Biochemical Toxicology of Acetaminophen, Rev Biochem. Toxicol., Vol. 2, 103-129 (1980).

23. S.D. NELSON, Metabolic Activation and Drug Toxicity, J. Med. Chem., Vol. 25, 753-765 (1982).

24. D.J. JOLLOW, S.S. THORGIERSSON, W.A. POTTER, M. HASHIMOTO and J.R. MITCHELL, Acetaminophen-Induced Hepatic Necrosis. Metabolic Disposition of Toxic and Nontoxic Doses of Acetaminophen, Pharmacology, Vol. 12, 251-271 (1974).

25. R.J. Mc MURTRY, W.R. SNODGRASS and J.R. MITCHELL, Renal Necrosis, Glutathione Depletion, and Covalent Biding after Acetaminophen, Toxicol. App. Pharmacol., Vol. 120, 87 100 (1978).

26. C.L. MIRANADA, M.C. HENDERSON, J.A. SCHMITZ and D.R. BUHLER, Protective Role of Dietary Butylated Hydroxyanisole against Chemical - Induced Acute Liver Damage in Mice, Toxicol. Appl. Pharmacol., Vol. 69, 73-80 (1983).

27. R.P. BATZINGER, S.-Y.L. OU and E. BUEDING, Anti-Muta- 
genic Effects of 2(3)-tert-butyl-Hydroxyanisol and of Antimicrobial Agents, Cancer Res., Vol. 38, 4478-4485 (1978).

28. P. MEHLEN, C. KRETZ-REMY, X. PREVILLE and A.P. ARRIGO, Human Hsp27, Drosophila Hsp27 and Human AlphaB-Crystallin Expression-Mediated Increase in Glutathione is Essential for the Protection of These Proteins against TNFalpha-Induced Cell Death, EMBO. J., Vol. 15, 2695-2706 (1996).
29. T. ROGALLA, M. EHRNSPERGER, X. PREVILLE, A. KOTLYAROV, G. LUTSCH, C. DUCASSE, C. PAUL, M. WIESKE, A.P. ARRIGO, J. BUCHNER and M. GAESTEL, Regulation of Hsp27 Oligomerization, Chaperone Function and Protective Activity against Oxidative Stress/Tumor Necrosis Alpha by Phosphorylation, J. Biol. Chem., Vol. 274, 18947-18956 (1999). 